\section{Numerical Study of Epoxy-Ramie Fiber Composite as a Type IV Ballistic Resistant Material}

\author{
Sutiknd Rayhan Fikriandry Rizal, Ahmat Safaat \\ Department of Mechanical Engineering, ITS, Sukolilo, Surabaya 60111, Indonesia \\ Received: 1 September 2020, Revised: 14 March 2021, Accepted: 20 March 2021
}

\begin{abstract}
This paper studies the response of epoxy-ramie fiber composite as ballistic-resistant material using a finite element model. The simulation test was conducted by varying the number of layers and referred to NIJ 0101.06 Type IV as the boundary condition. The model used was a panel made from epoxy-ramie composite laminates with a certain thickness and a $7.62 \mathrm{~mm}$ bullet. NIJ states that ballistic material should withstand penetration, and the back-face signature (BFS) should not exceed $44 \mathrm{~mm}$. The impact energy is not briefly mentioned in NIJ failure criteria. The properties of the composite and the bullet were obtained from scientific literature and previous study. The effect of the number of layers on impact response was evaluated by the penetration, deformation, BFS, and absorbed energy.
\end{abstract}

Keywords: Epoxy-ramie fiber, body armor, type IV NIJ 0101.06, finite element method

\section{Introduction}

In its study, the American Medical Association states that although since 1990 there has been a decrease in the overall firearms-related deaths, in 2016 alone, it was estimated that there were still 195,000 to 276,000 deaths from the same cause [1]. Nowadays, to minimize the case, the military and police force of countries worldwide have used ballistic resistant materials as vehicle and body armor panel. NIJ 0101.06 issued by the National Institute of Justice (NIJ) under the US Department of Justice states several requirements of ballistic resistant materials where the penetration and back-face signature (BFS) are the main requirements that must be met. The bullet should not fully perforate the panel, and the BFS should not exceed $44 \mathrm{~mm}$. There are several types of ballistic resistance materials depends on the types of bullet [2].

Most of the bulletproof panels are made of metals, ceramic, and composite [3,4]. Metals generally have greater density than composites. The most common ballistic composite material is made from para-aramid fiber such as Kevlar and Twaron. They have a strength-to-density ratio higher than metals. Unfortunately, the International Union Conservative of Nature states that synthetic fiber contributes $35 \%$ of microplastic presence in the ocean.

Ramie fiber (Bohemia Nivea) is one of the natural fibers that can be used as a reinforcement for composite materials. The performance of ramie fiber as reinforcement in bullet-proof composite panels has been examined. Ramie-fiber epoxy composite panels can withstand type I ballistic threats [5]. Indonesian Institute of Sciences (LIPI) has stated that ramie fiber has high potential and mechanical properties almost comparable to Kevlar fiber [6, 7].
The price and performance comparisons between ramie fiber-reinforced composites and Kevlar fiber-reinforced composites have been examined, and it is concluded that ramie fiber-reinforced composites have ballistic characteristics close to Kevlar fiber-reinforced composites, but with a significant price reduction [8]. Several studies concluded that ramie fiber is the strongest cellulose-based natural fiber, making it suitable as an alternative material in the manufacture of bullet-proof composite panels [9, 10].

Many experimental studies regarding the ballistic response of a composite material have been carried out. However, the design, performance, and evaluation of composite panels undergoing ballistic impact testing require an initial understanding of the material's characteristics under high-speed impact. In 2000-2010, many numerical models described the impact load on woven composites. However, most of these models deal with the low-speed impact, such as drop weight testing [11-13].

In this study, a numerical model of a thin epoxy and woven ramie fiber composite lamina with a certain thickness was made using the dimensions of a ballistic test specimen standard stated in the National Institute of Justice (NIJ) [2]. The previous studies' mechanical properties data were used as a further basis for the specimen modeling [14]. The model was then configured to increase the number of layers until a minimum thickness that met the ballistic standard NIJ 0106.01 type IV was obtained. Such modeling was expected to simulate hard armor made of laminate structured composites with specific response characteristics on receiving type IV ballistic threats.

\footnotetext{
*Corresponding author. Email: sutikno.its@gmail.com
} 


\section{Procedure}

\subsection{Model Development}

The geometry of the model used refers to NIJ 0101.06 testing standard level IV. The projectile used in the test was $7.62 \mathrm{~mm}$ Armor-piercing bullets which commonly used in long-barreled firearms. The mechanical properties applied to the bullet model were adjusted to the material to be used in common [4, 11]. The panel had a dimension of $254 \times 305 \mathrm{~mm}(10 \times 12$ in) with $2 \mathrm{~mm}$ thickness for each layer. The properties of epoxy-ramie fiber composite panel were obtained from the previous study as mentioned in Table 1. The test model geometry is shown in Figure 1. The model procedure has been taken from many references and previous study [2, 15, 19].

\subsection{Boundary Condition}

The boundary condition of this simulation was adopted from NIJ 0101.06 with several adjustment as mentioned in Figure 2, All sides of the panel in all layers were conditioned as fixed support to make the panel stay in place and not be displaced by the projectile. The bullet was positioned close to the panel to minimize the time of running the simulation. The bullet had a velocity of $878 \mathrm{~m} / \mathrm{s}$ straight to the panel at the z-axis. The $\mathrm{x}$ and $\mathrm{y}$ displacement was set to be zero meanwhile $\mathrm{z}$ displacement was set to be free. This is done so that the projectile body may only be displaced, or in this case, deformed, in the direction of the y-axis. This will practically make the projectile a rigid body [16].

Table 1. Mechanical properties of epoxy-woven ramie fiber composite

\begin{tabular}{|l|l|l|}
\hline \multicolumn{1}{|c|}{ Properties } & \multicolumn{1}{c|}{ Value } & Units \\
\hline Maximum Force & $6,510.9$ & $\mathrm{~N}$ \\
\hline Area & 65.005 & $\mathrm{~mm}^{2}$ \\
\hline Ultimate Tensile Strength & 100.160 & $\mathrm{MPa}$ \\
\hline Modulus of Elasticity & 885.189 & $\mathrm{MPa}$ \\
\hline Poisson Ratio & 0.071 & - \\
\hline
\end{tabular}

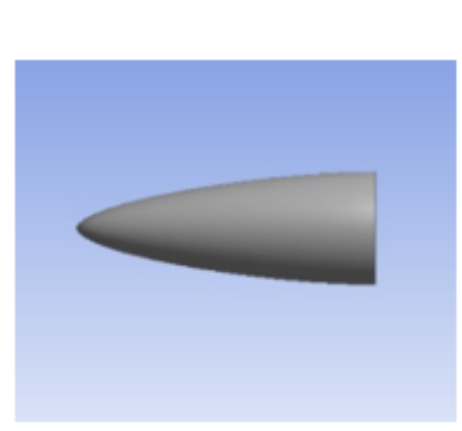

(a)

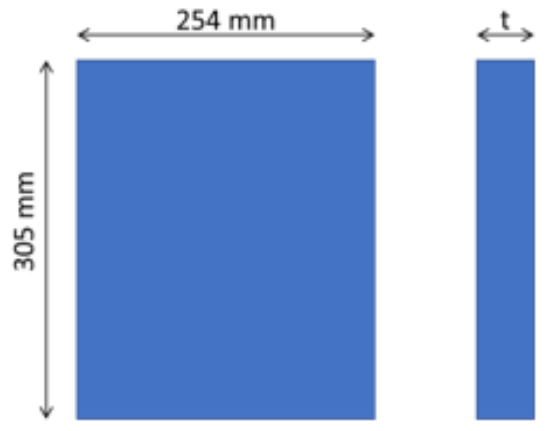

(b)

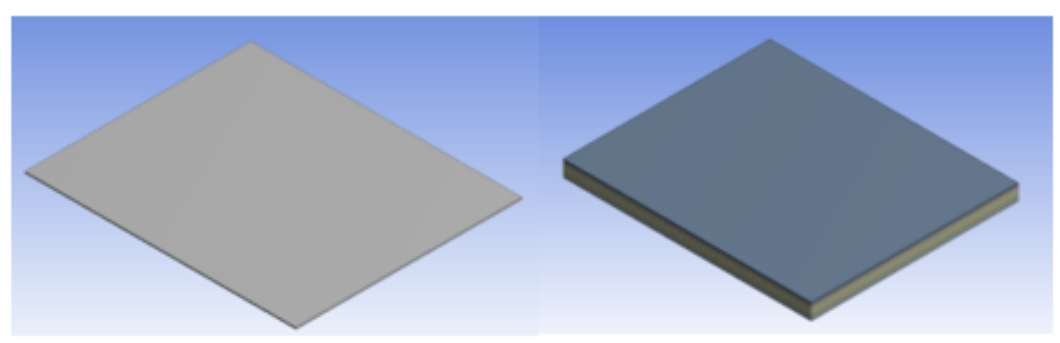

(c)

(d)

Figure 1. (a) $7.62 \mathrm{~mm}$ AP model (b) Panel geometry (c) 1-layered model (d) 10-layered model 


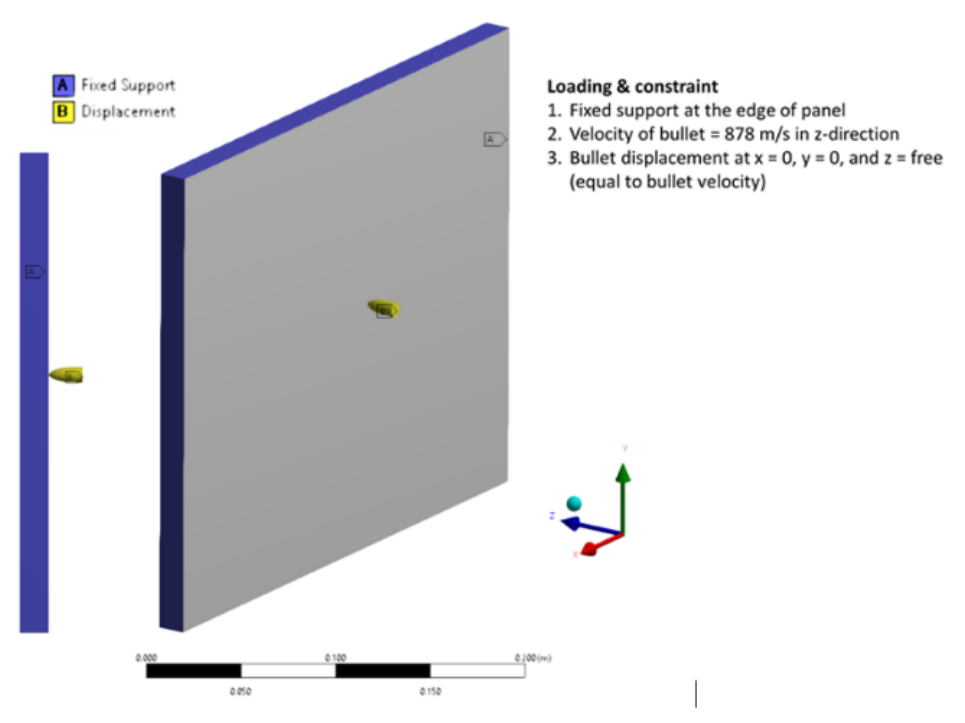

Figure 2. Modelled boundary condition [15, 16]

\section{Results and Discussion}

\subsection{Penetration and BFS}

The penetration occurs when the strength of panel cannot withstand the impact of the bullet. The penetration and BFS are mentioned in Table 2 below. The values listed in Table 2 were measured coincidentally with the time when the projectile velocity was zero. This was done so that value comparisons can be carried out based on similar conditions between one-panel variations to another. The depth of penetration is the distance the projectile has traveled from the surface of the front-most layer of the panel until it loses its kinetic energy or velocity, while BFS is the highest displacement on the back face of the panel.

The BFS decreased with the increase of panel thickness, while the penetration had a relatively constant value around $27-28 \mathrm{~mm}$ for 12 layers and above. The projectile has completely penetrated both 10 and 11-layered, so they do not require BFS measurements. BFS was obtained by showing the displacement of the back surface of the rear layer.

\subsection{Energy due to collision}

The total energy in the initial condition equals bullet kinetic energy $\left(E k_{1}\right)$, while the initial energy in the panel is always zero. All changes that occurred are due to the absorption of the kinetic energy of the projectile $\left(E k_{1}\right)$ that transforms into work $(W)$, deformation $\left(E_{\text {deform }}\right)$, panel damage ( $\left.E_{\text {damage }}\right)$, and/or continued to the subject or object behind the panel $\left(E k_{2}\right)$. In this numerical modeling, the kinetic energy of the projectile transformed into panel kinetic energy ( $\left.E_{\text {kinetic panel }}\right)$, panel internal energy ( $\left.E_{\text {internal panel }}\right)$, and panel total energy ( $\left.E_{\text {total panel }}\right)$.

Table 2. Penetration and BFS from simulation

\begin{tabular}{|c|c|c|c|c|}
\hline $\begin{array}{c}\text { Amount } \\
\text { of } \\
\text { layer }\end{array}$ & $\begin{array}{c}\text { Thickness } \\
(\mathbf{m m})\end{array}$ & $\begin{array}{c}\text { Penetration } \\
(\mathbf{m m})\end{array}$ & Status & $\begin{array}{c}\text { BFS } \\
(\mathbf{m m})\end{array}$ \\
\hline 10 & 20 & 28.381 & Through & - \\
\hline 11 & 22 & 28.080 & Through & - \\
\hline 12 & 24 & 27.765 & - & 5.42 \\
\hline 13 & 26 & 27.822 & - & 2.47 \\
\hline 14 & 28 & 27.767 & - & 1.60 \\
\hline 15 & 30 & 27.690 & - & 1.33 \\
\hline 16 & 32 & 27.637 & - & 1.08 \\
\hline 17 & 34 & 27.852 & - & 0.92 \\
\hline 18 & 36 & 27.753 & - & 0.76 \\
\hline 19 & 38 & 27.764 & - & 0.6597 \\
\hline 20 & 40 & 27.833 & - & 0.6577 \\
\hline
\end{tabular}




$$
\begin{aligned}
E_{1} & =E_{2}=E_{3} \\
E_{1} & =E_{k 1} \\
E_{1} & =E_{\text {total panel }}+E_{k 2} \\
E_{k 1} & =\left(E_{\text {internal panel }}+E_{\text {kinetic panel }}\right)+E_{k 2} \\
E_{k 1} & =\left(W+E_{\text {deform }}+E_{\text {demage }}\right)+E_{k 2} \\
E_{k 1} & =\left(E_{\text {transferred }}+E_{\text {loss }}\right)+E_{k 2}
\end{aligned}
$$

where:

$$
\begin{array}{ll}
E_{1} & =\text { initial total energy }(\mathrm{J}) \\
E_{2} & =\text { energy at collisions }(\mathrm{J}) \\
E_{2} & =\text { energy after collisions }(\mathrm{J}) \\
W & =\text { work }(\mathrm{J}) \\
E_{1} & =E_{k 1}
\end{array}
$$

\subsection{Panel Kinetic Energy}

Kinetic energy is defined as the energy used by the panel to displace itself refers to its initial condition. However, because all sides of the panels have been made as fixed support, the panel would be fixed in its position. Hence, any further panel displacement because of the external forces may only occur in a very specific way, which is vibration. The panel can vibrate due to the projectile's kinetic energy, which is absorbed into the internal energy of the panel and then released back into the environment in the form of elastic deformation, which continues to occur due to the flexibility of the panel material and deflection. The value of the panel kinetic energy shown in Figure 3 is evaluated at the time when the maximum penetration occurs at each panel variation. The figure shows that with the increase of the amount layers on the panel, a decreasing trendline is observed. This indicates that increasing the layer will generally make the panel stiffer. Therefore, elastic deformation requires more energy to occur.

\subsection{Panel Internal Energy}

Internal energy is equal to the energy absorbed and used by the panel to deform due to its collision with the projectile. Deformation can be both elastic and plastic depends on the time at which the deformation is evaluated. All the energy values shown in Figure 3 and Figure 4 are evaluated when the projectile loses its kinetic energy and reaches its maximum penetration depth. It is known from the figure that the graph has a decreasing trendline. This indicates that adding more layers made less energy absorption than before.

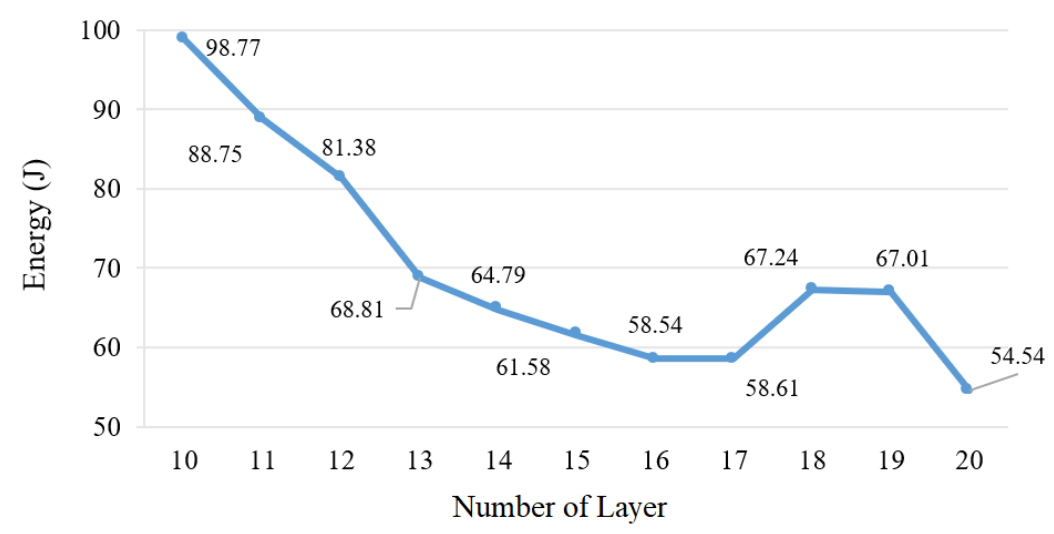

Figure 3. Panel kinetic energy

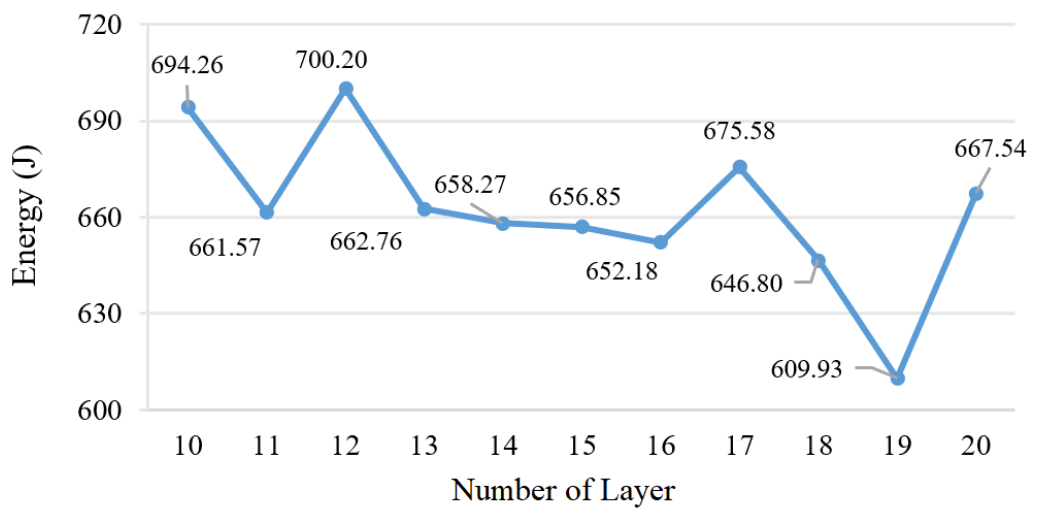

Figure 4. Panel internal energy 
Such indication may not be a fair comparison in general because the value of deformation due concurring to the internal energy in each panel variation is still not yet known. Figure 5 shows the total deformation value experienced by each panel variation. The total deformation is the resultant of the displacement vectors experienced by each meshing element on the modeled panel. The value in Figure 6 is obtained by dividing the internal energy value with the total deformation value on each panel variation.

From Figure 5, the deformation getting smaller while the number of layers is increased, but from Figure 6, the energy required to make the panel deform is getting bigger. This is also in accordance with the previous discussion about the panel kinetic energy. As the number of layers increases, the more difficult it is for the panel to experience elastic deformation. However, since the internal energy also defines the value of energy absorbed and used by the panel to deform plastically, it can be concluded that with the increasing number of layers, the panel also becomes more resilient.

\subsection{Panel Total Energy}

Panel total energy is the amount of energy the panel as the result of impact with the projectile, which is the summation of kinetic, internal, and lost energy. Both of total and internal energy has equal trend with each other with energy loss as the offset. This offset is due to the friction contact between bullet and panel, thermal energy, and internal work in the panel. The sum of internal and kinetic in Figure 7does not exactly equal the total energy due to numerical error.

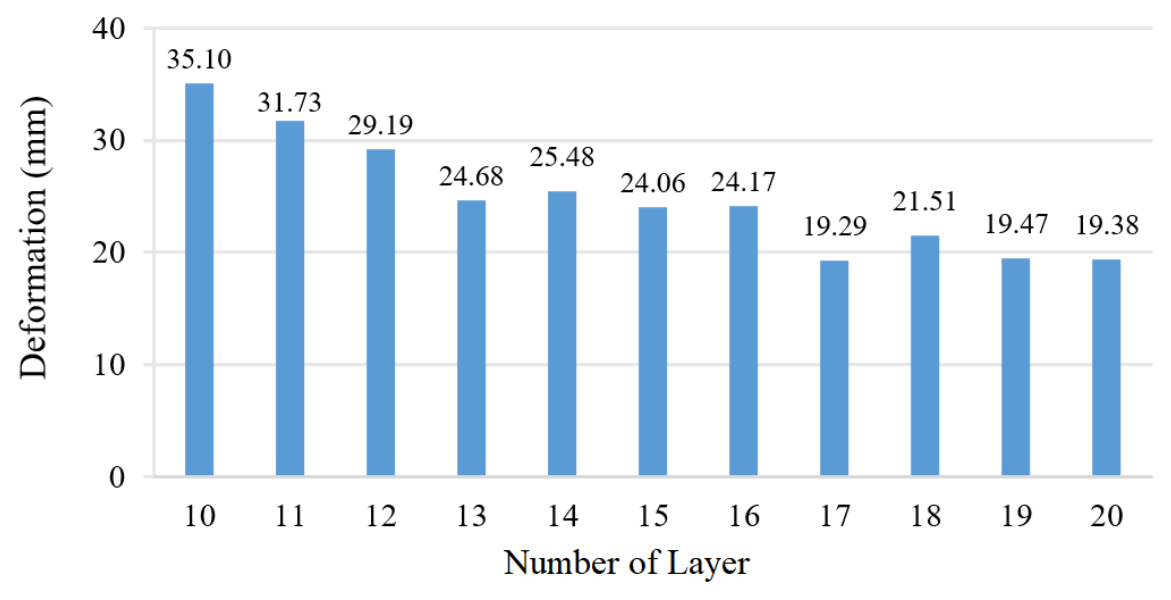

Figure 5. Panel total deformation

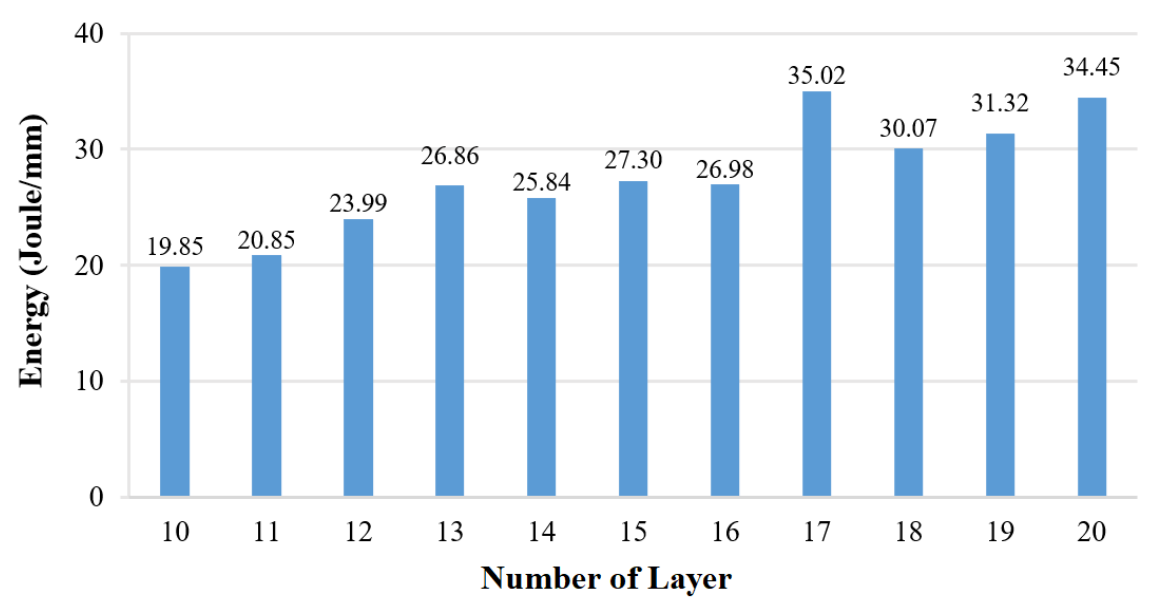

Figure 6. Required energy to deform panels 


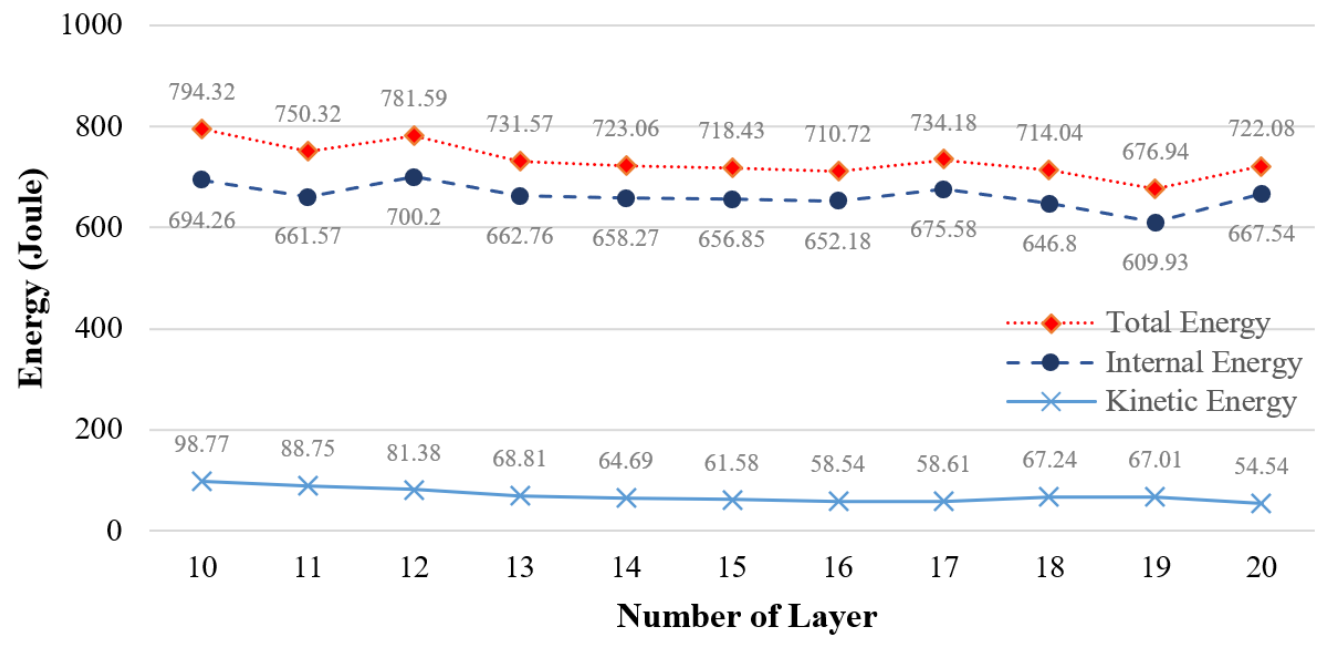

Figure 7. Energy in the panel

\subsection{Energy Loss}

The amount of energy loss can be determined by evaluating layers failure. This indication can also be a determinant that will distinguish whether the projectile has penetrated all existing layers on the panel or whether some amount of layers have successfully held back the projectile by absorbing its kinetic energy by deforming without a failure. Such indication can be done subjectively by viewing the panel's side profile and confirming whether the projectile has penetrated the panel all the way through or not. However, it can also be carried out objectively by evaluating and analyzing whether each layer on the panel has failed due to penetration by calculating the energy loss due to the strain energy being released into the environment from such failure. This can be done using the total energy data possessed by each layer on the panel in question.

Table 3 shows that 10 and 11-layered panel have been completely penetrated by the projectile because all layer on both panels has been observed to experience failure. It is known that increasing the number of layers on the panel will increase the energy lost due to layer failure. This proves that although the projectile stops at relatively different times and depths of penetration, the energy required to penetrate the panel increases when the number of layers is increased. This proves that the panel is more stiff and tough with the increased number of layers. Along with the total deformation value of the panel, it is hoped that the value of energy loss will help to explain why the panel's internal energy and total energy decrease as more layers are added. As an example, there are 277.57 Joules of lost energy on the 10-layered panel in Figure 8, In the process of stopping the projectile, the 10-layered panel must compensate for its high internal work by performing a lot of both elastic and plastic that may further lead to complete failure of the panel. This because a 10-layered panel is not able to effectively absorb the projectile kinetic energy, especially when compared to panels that have more layers. Therefore, the layers on the 10-layered panel can be completely penetrated by the projectile using a relatively low amount of energy, and the remaining intact body of all said penetrated layers must absorb the remaining kinetic energy of the projectile by carrying out greater deformation so that the projectile advancement can be stopped.

Table 3. Penetration on panel

\begin{tabular}{|c|c|c|c|}
\hline $\begin{array}{c}\text { Amount } \\
\text { of } \\
\text { Layer }\end{array}$ & $\begin{array}{c}\text { Penetrated } \\
\text { Layer }\end{array}$ & $\begin{array}{c}\text { Intact } \\
\text { layer }\end{array}$ & $\begin{array}{c}\text { Energy } \\
\text { Loss } \\
\text { (J) }\end{array}$ \\
\hline 10 & 10 & 0 & 277.567 \\
\hline 11 & 11 & 0 & 325.384 \\
\hline 12 & 11 & 1 & 330.081 \\
\hline 13 & 12 & 1 & 338.174 \\
\hline 14 & 12 & 2 & 341.59 \\
\hline 15 & 12 & 3 & 344.485 \\
\hline 16 & 12 & 4 & 343.6147 \\
\hline 17 & 13 & 4 & 401.4606 \\
\hline 18 & 13 & 5 & 391.8878 \\
\hline 19 & 13 & 6 & 447.4526 \\
\hline 20 & 13 & 7 & 405.2644 \\
\hline
\end{tabular}




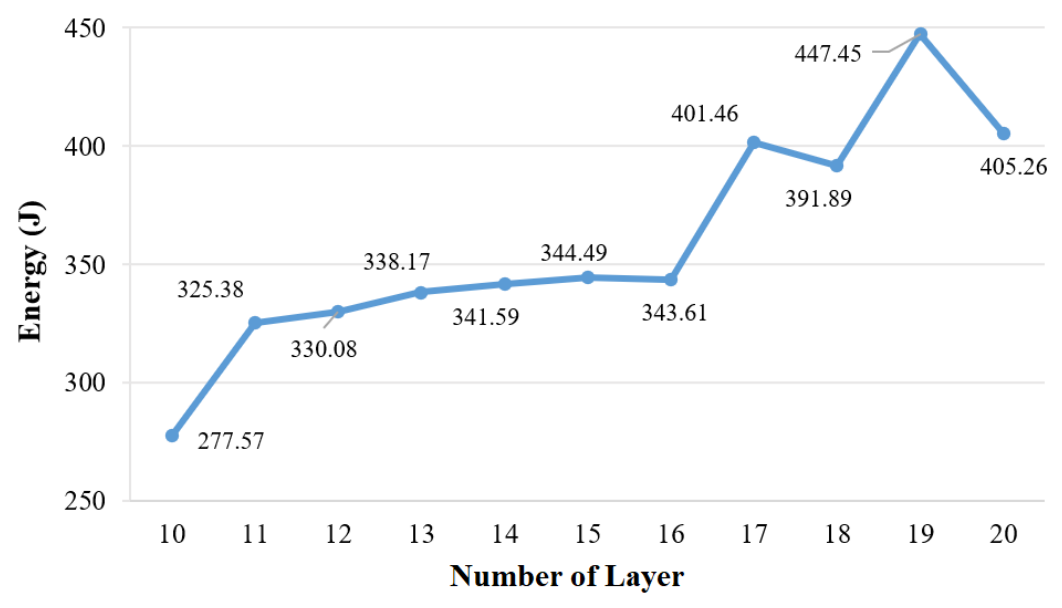

Figure 8. Energy loss due to layer failure on the panel

\subsection{Energy Loss}

If the panel's total energy and energy lost due to failure are known, the amount of transferred energy to the object or the subject the panel protects can be calculated. Using the energy conservation principle, which states that the initial energy of the projectile must match the cumulative value of the final energy on the panel, and if any discrepancy is present between the two, then the value of such discrepancy should be the amount of energy passed on by the panel to the object or subject behind it. Based on table 4, all panel variations managed to absorb and/or divert more than 1000 Joules of the projectile's kinetic energy. The fluctuation in the transferred energy value directly relates to how much damage presents due to failure and how much deformation occurs in the panel. For example, 10, 11, and 12-layered panels are known to transfer more energy than the variations in the number of layers 13, 14, 15, and 16-layered panels. This is because 10,11 , and 12-layered panel suffers a lot of damage due to localized layer failure, and they also have a lot of deformation as compensation for the lack of necessary stiffness and toughness that is required to stop the projectile within the range of acceptable damage.

However, it is important to remember that the projectile completely penetrated the 10 and 11-layered panels. Even though the energy transferred had greater value than several other panel variations, both panels were deemed as a failure. The values in Table 4 are evaluated on the assumption that the body of the object or subject being protected does not have any contact with the panel's back surface. Even the panel was completely penetrated, the layers still had the free area to flex and deform while continuing to carry out the work of stopping the projectile, without some of its kinetic energy being transmitted to the body of the object or subject being protected. If 10 and 11-layered panels were applied as body armor, the user would have been seriously injured. This is because exactly when the projectile breach the rearmost layer on both panels, the projectile itself had not stopped moving. The projectile still has a certain amount of kinetic energy, which will then be transferred to the user body. In Figure 9. it is known that increasing the number of layers has succeeded in decreasing the transferred energy value to the object or subject behind the panel.

\subsection{Panel of Performance}

One of the determining factors that can assess type IV ballistic resistant materials' performance is how much energy can be transferred per unit mass of the component used. The protective material is expected to receive and transfer the projectile's kinetic energy as much as possible with very light mass. This is because the use of ballisticresistant protective materials is always associated with conditions of high intensity and mobility. So, users will always benefit if the protective material used has high protective effectiveness in a light mass.

In Figure 10, the 12-layered panel is the most effective in carrying out its work as a type IV ballistic resistant material. The 10 and 11 layered panels were not evaluated because they had holes due to complete projectile penetration. The curve appears to have a decreasing trendline as the number of layers increases. This is because the increase in mass along with the addition of layers does not provide a significant advantage in energy absorption. However, it is important to note that the deformation of panels with a higher number of layers is smaller than others. This can be a basis of argument where panels with many layers may have higher effectiveness if there are multiple projectiles that are about to hit the panel. This is because the panel will have the opportunity to absorb and divert additional energy from the next projectiles that will hit it, where at the same time, it is possible that the panels with a lower number of layers will fail to carry out their work due to the plastic deformation that occurs in these panels are nearing the material strain limit. 


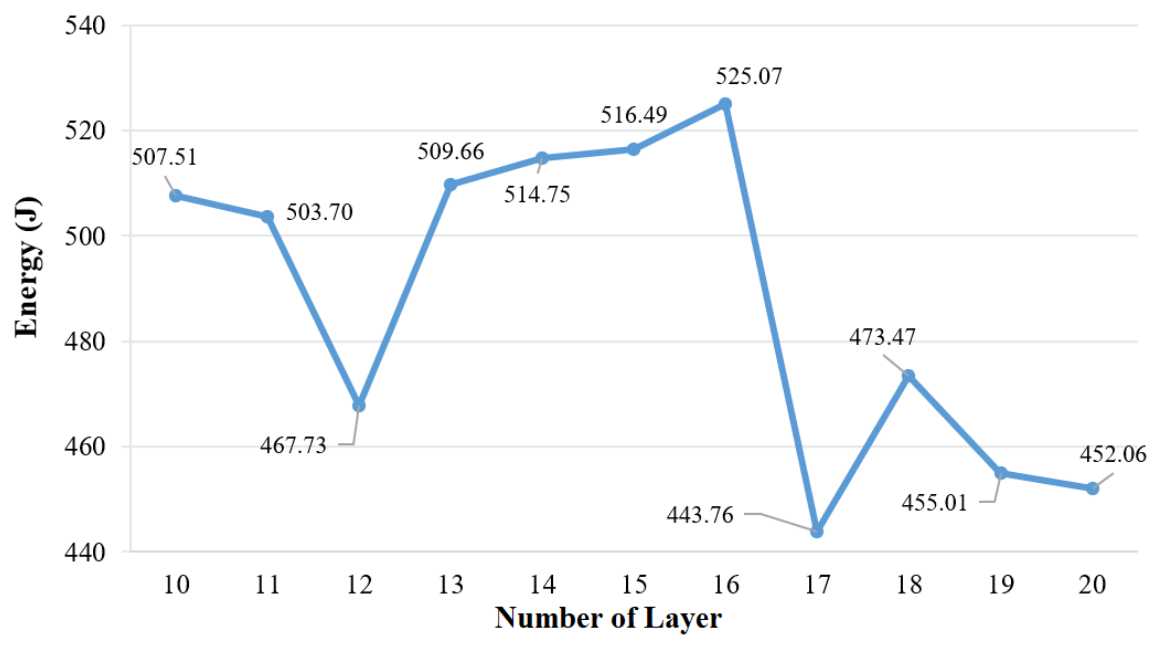

Figure 9. Transferred energy curve

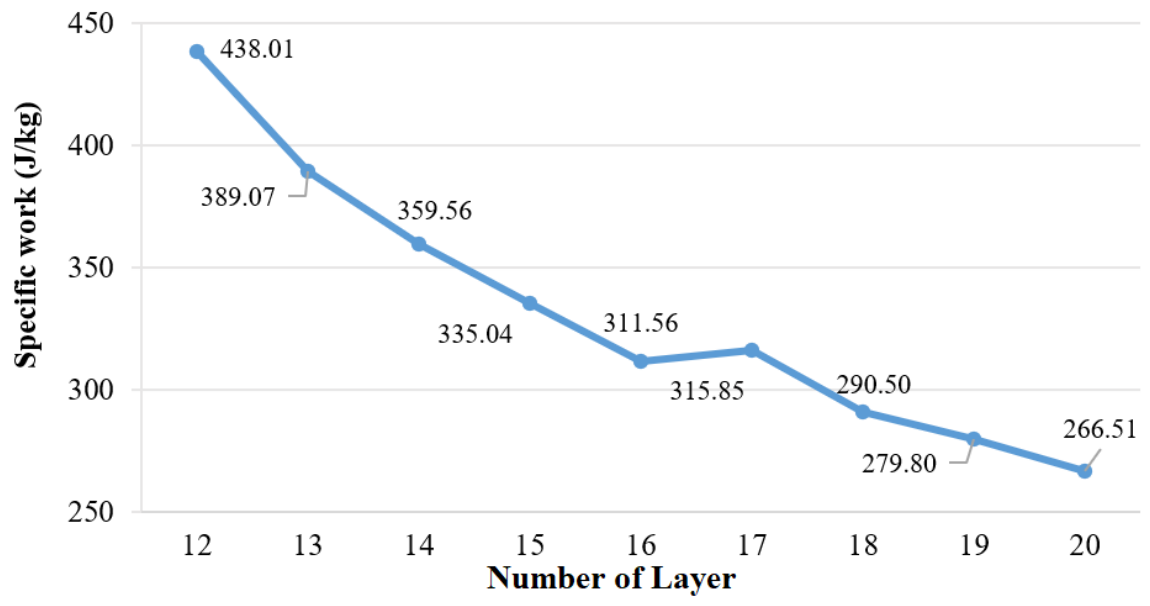

Figure 10. Panel specific work

To get high effectiveness in absorbing the kinetic energy, the panel needs to be penetrated by the projectile to a certain layer. All remaining intact layers on the panel are required to undergo plastic deformation. This is because the kinetic energy of the projectile, which the panel uses to deform elastically, is actually transformed into the panel's kinetic energy. Compared to the panel internal energy for plastic deformation, the panel kinetic energy has a minimal value. Panel kinetic energy will eventually return to zero because it will eventually reach a state of equilibrium where it no longer moves or vibrates. In the end, the elastic deformation does not contribute significantly to the absorption of the projectile kinetic energy.

The 13-layered epoxy-ramie panel had the best performance for a single impact. The BFS of the 13-layered panel has met the NIJ 0101.06 standard, and the greatest stress on the rearmost layer of the panel has just passed the stress material yield. It can be confirmed that the rearmost layer of the panel has also performed some plastic deformations, hence increasing the energy absorption effectiveness of the overall panel.

\section{Conclusion}

It can concluded in this study that the epoxy-ramie woven laminated composite panel with 10 and 11-layered panels were completely penetrated by the projectile, while $12,13,14,15,16,17,18,19$, and 20-layered panels were not completely penetrated by the projectile. The panels that were not penetrated by projectile had BFS below 44 $\mathrm{mm}$, and it met the requirement stated in NIJ 0101.06.

The best configuration within the constraint of this study was 13-layered panel. The 13-layered panel met the penetration and BFS requirements according to NIJ 0101.06 type IV. All layers that were not penetrated by the projectile on the 13-layered panel underwent plastic deformation, so that all layers played an active role in absorbing or diverting the kinetic energy. The panel were not in an imminent failure state. With a value of 389.07 Joules $/ \mathrm{kg}$, the 13-layered panel had the second largest specific work value compared to all panel variations on 
this study. The highest specific work value was owned by the 12-layered panel with a value of 438.01 Joule, but because the 12-layered panel was at the state of imminent failure, the 12-layered panel cannot be declared as an optimal configuration.

\section{References}

[1] H. Bauchner, F. P. Rivara, R. O. Bonow, N. M. Bressler, M. L. N. Disis, S. Heckers, S. A. Josephson, M. R. Kibbe, J. F. Piccirillo, R. F. Redberg, et al., "Death by gun violence-a public health crisis," JAMA, vol. 318, no. 18, pp. 1763-1764, 2017.

[2] N. I. o. J. US Department of Justice, Ballistic Resistance of Body Armor. National Institute of Justice: Washington, D.C. United States, 2008.

[3] S. Burton, "36 important facts about body armor," Bodyarmornews. https://www.bodyarmornews.com/all-about-bodyarmor-36-facts, (accessed on 14 May 2020).

[4] Engarde, "Bendable, flexible soft armor panels," https://www.engardebodyarmor.com/soft-armor, (accessed on 17 May 2020).

[5] Suryaneta, Kinerja Serat Rami sebagai Reinforcement pada Polimer Komposit Panel Anti Peluru. Perpustakaan Universitas Indonesia, 2007.

[6] R. Adistya, SIFAT MEKANIK BIOKOMPOSIT SERAT RAMI (BOEHMERIA NIVEA L.) DENGAN MATRIKS POLIPROPILLEN. Perpustakaan Institut Pertanian Bogor, 2013.

[7] F. de Oliveira Braga, T. L. Milanezi, S. N. Monteiro, L. H. L. Louro, A. V. Gomes, and É. P. Lima Jr, Ballistic Comparison Between Epoxy-Ramie and EpoxyAramid Composites in Multilayered Armor Systems. Department of Materials Science Military Institute of Engineering: Rio de Janeiro, Brazil, 2017.

[8] Pusat Penelitian Fisika LIPI, "Baju tahan peluru dari serat rami," http://www.fisika.lipi.go.id/webfisika/content/bajutahan-peluru-dari-serat-rami (accessed on 28 May 2020), 2009.

[9] A. F. H. M. Mujiyono, Didik Nurhadiyanto, Rekayasa Panel Tahan Peluru Level IV Standar NIJ dari Komposit Serat Rami dan Hardfacing Material HV1000 dengan Matriks Epoxy. Perpustakaan Universitas Negeri Surakarta, 2016.

[10] N. Naik, P. Shrirao, and B. Reddy, "Ballistic impact behaviour of woven fabric composites: Formulation," International Journal of Impact Engineering, vol. 32, no. 9, pp. 1521-1552, 2006.

[11] Premier Body Armor, "Bulletproof backpack armor," https://premierbodyarmor.com/collections/bulletproofbackpack-inserts-all (accessed on 1 May 2020).

[12] T. P. Soemardi, W. Kusumaningsih, and A. P. Irawan, "Karakteristik mekanik komposit lamina serat rami epoksi sebagai bahan alternatif soket prostesis," Makara Journal of Technology, vol. 13, no. 2, p. 149230, 2009.

[13] A. P. Irawan, T. P. Soemardi, K. Widjajalaksmi, and A. H. Reksoprodjo, "Tensile and flexural strength of ramie fiber reinforced epoxy composites for socket prosthesis application," 2011.

[14] A. F. H. MUKHAMMAD, Studi kelayakan komposit hybrid epoksi-anyaman serat rami dan SS 304L screen mesh sebagai panel tahan peluru level II standar NIJ. $\mathrm{PhD}$ thesis, Universitas Gadjah Mada, 2010.

[15] A. Safaat, K. H. Fendy, et al., "Natural fiber reinforced composites as bulletproof panel materials," in Key Engineering Materials, vol. 867, pp. 82-90, Trans Tech Publ, 2020.

[16] Sutikno, W. Ashari, and R. Azhari, "Ballistic performance test of multiple reinforcements composite armor vest," in AIP Conference Proceedings, vol. 1983, p. 050010, AIP Publishing LLC, 2018.

[17] S. Abrate, "Modeling of impacts on composite structures," Composite Structures, vol. 51, no. 2, pp. 129138, 2001.

[18] M. Ravid, S. Bodner, and I. Holcman, "Analysis of very high speed impact," International Journal of Engineering Science, vol. 25, no. 4, pp. 473-482, 1987.

[19] I. Iváñez del Pozo, C. Santiuste Romero, E. Barbero Pozuelo, and S. Sánchez Sáez, "Numerical modelling of foam-cored sandwich plates under highvelocity impact," Compos. Struct, vol. 93, no. 9, pp. 2392-2399, 2011. 